\title{
MEMBANGUN WEBSITE PROFILE KELURAHAN MELAYU TENGGARONG
}

\author{
Yulindawati $^{1}$ dan Hanifah Ekawati ${ }^{2}$ \\ STMIK Widya Cipta Dharma ${ }^{1,2}$ \\ Jl. M. Yamin No. 25, Samarinda, 75123 \\ E-mail : Yuli.linda08@yahoo.com¹ ${ }^{1}$ hanifah@wicida.ac.id ${ }^{2}$
}

\begin{abstract}
The research to build Website Profile of Tenggarong Kelurahan is a study to facilitate the public to obtain complete and up-to-date information because the information is felt to be very important in decision making and in achieving goals. In addition to obtaining complete and up-todate information, the website can also send and publish information to the wider community online. The system development method used in this research is the System Development Life Cycle (SDLC) method, or better known as the system development life cycle in system engineering and software engineering, is the process of making and changing systems and the models and methodologies used to develop these systems. The long-term goal to be achieved is that it is hoped that this system will be able to publicize its activities for more up-to-date information so that the public can find out about the activities that have been carried out, ease of information on the procedures for handling correspondence in the Melayu Tenggarong village to the public at large. So that the specific target of using the Tenggarong Kelurahan website as an effective medium for delivering information can be achieved.
\end{abstract}

Keywords: Website Profile, SDLC, Information System, Tenggarong, Keluarahan Melayu Tenggarong

\begin{abstract}
Abstrak : Penelitian membangun Website Profile Kelurahan Melayu Tenggarong merupakan penelitian untuk mempermudah masyarakat memperoleh informasi yang lengkap dan terbaru karena informasi di rasa sangat penting dalam pengambilan keputusan dan dalam mencapai tujuan. Selain memperoleh informasi yang lengkap dan terbaru, website juga dapat mengirim serta mempublikasikan informasi kepada masyarakat luas secara online. Metode Pengembangan sistem yang digunakan penelitian yaitu metode (SDLC) System Development Live Cycle atau yang lebih dikenal siklus hidup pengembangan sistem dalam rekayasa sistem dan rekayasa perangkat lunak adalah proses pembuatan dan pengubahan sistem serta model dan metodologi yang digunakan untuk mengembangkan sistem-sistem tersebut. Tujuan jangka panjang yang ingin dicapai adalah diharapkannya sistem ini dapat mempublikasikan kegiatannya untuk informasi yang lebih terbaru lagi sehingga masyarakat dapat mengetahui kegiatan-kegiatan yang telah dilakukan, kemudahan informasi prosedur-prosedur surat menyurat pengurusan di daerah kelurahan melayu tenggarong kepada masyarakat secara luas. Sehingga target khusus menggunakan website kelurahan melayu tenggarong sebagai media penyampaian informasi yang efektif dapat tercapai.
\end{abstract}

Kata kunci: Website Profile, SDLC, Sistem Informasi, Tenggarong, Kelurahan Melayu Tenggarong.

\section{PENDAHULUAN}

Saat ini adalah zamannya internet dimana batasan waktu dan jarak tidak berarti lagi bagi media yang satu ini. Kita dapat berkomunikasi dengan siapa saja dan dimana saja di seluruh dunia ini dengan menggunakan fasilitas e-mail maupun dengan cara chatting. Mungkin pada saat ini hampir setiap orang sudah memiliki email untuk dapat bergabung di internet [1].

Perkembangan teknologi dewasa ini semakin pesat dan semakin akrab menyentuh 
kehidupan manusia. Manusia yang dalam hal ini sebagai user menginginkan untuk dapat memperoleh informasi yang lengkap serta terbaru [2]. Disinilah peran teknologi yang semakin maju sangat dibutuhkan, yaitu dalam upaya mewujudkan keinginan manusia tersebut, karena informasi di rasa sangat penting dalam pengambilan keputusan dan dalam mencapai tujuan. Selain daripada memperoleh informasi yang lengkap dan terbaru, perkembangan teknologi juga dapat mengirim serta mempublikasikan informasi kepada masyarakat luas secara online. Suatu instansi, perusahaan, organisasi dan lembaga dapat mempublikasikan usaha dan kegiatan secara online[3].

Kelurahan Melayu Tenggarong merupakan Instansi Pemerintahan yang membutuhkan suatu sistem untuk dapat mempublikasikan kegiatannya kepada Masyarakat secara online. Menyikapi hal tersebut, akan dibangun suatu sistem online berbasis Website di Kelurahan Melayu Tenggarong. Dengan membangun suatu Website profile dinamis. Media internet di jadikan sebagai sarana untuk dapat mempublikasikan kegiatannya kepada masyarakat luas di dalam dunia maya. Karena internet mempunyai jangkauan yang luas, dapat di akses oleh siapa saja dan kapan saja serta tidak terbatas oleh waktu.

Diharapkan dengan adanya sistem ini Ini Kelurahan Melayu Tenggarong dapat mempublikasikan kegiatannya untuk Informasi yang lebih terbaru lagi sehingga masyarakat dapat mengetahui kegiatan-kegiatan yang telah di lakukan kemudahan informasi prosedur- prosedur surat menyurat pengurusan di daerah Kelurahan Melayu Tenggarong.

\section{METODOLOGI PENELITIAN}

\subsection{Teori}

Penelitian ini meliputi beberapa teori, antara lain:

\section{a) Website}

Website adalah sebuah kumpulan halaman yang diawali dengan halaman muka yang berisikan informasi, iklan, serta program aplikasi[4]. Website adalah suatu layanan sajian informasi yang menggunakan konsep hyperlink, yang memudahkan surfer (sebutan para pemakai komputer yang melakukan browsing atau penelusuran informasi melalui internet). Jadi Website merupakan halaman situs sistem informasi yang dapat diakses secara cepat.[5]

\section{b) Internet}

Internet adalah sebuah sistem komunikasi global yang menghubungkan komputerkomputer dan jaringan-jaringan komputer di seluruh dunia. Setiap komputer dan jaringan terhubung secara langsung maupun tidak langsung ke beberapa jalur utama yang disebut internet backbone yang membedakan antara satu dan yang menggunakan unique name yang biasa disebut dengan alamat IP 32 bit.[6]

\section{c) CSS (Cascade Style Sheet)}

CSS merupakan singkatan dari Cascade Style Sheet, yaitu script yang digunakan untuk mengatur desain website. Fungsi CSS adalah memberikan pengaturan yang lebih lengkap agar struktur website yang dibuat dengan HTML terlihat lebih rapi dan indah.[7] 


\section{d) DataBase (Basis Data)}

Basis Data merupakan suatu kumpulan data yang berhubungan secara logis dengan deskripsi data tersebut, yang di rancang untuk memenuhi informasi yang dibutuhkan oleh suatu organisasi. Artinya, basis data merupakan tempat penyimpanan data yang besar, dimana dapat digunakan oleh banyak pengguna. Seluruh item basis data tidak lagi dimiliki oleh satu departement, merupakan menjadi sumber daya perusahaan yang dapat digunakan bersama.[8]

e) PHP Hypertext Prepocessor

PHP adalah suatu bahasa scripting khususnya digunakan untuk web development. Karena sifatnya yang server side scripting, maka untuk menjalankan PHP harus menggunakan web server.[9] PHP juga dapat diintegrasikan dengan HTML, JavaScript, Jquery. Namun, pada umumnya PHP lebih banyak digunakan bersamaan dengan file bertipe HTML. Dengan menggunakan PHP kita bisa menggunakan website powerful yang dinamis dengan disertai manajemen databasenya. Selain itu juga penggunaan PHP yang sebagian besar dapat jalan di banyak platform, menjadi salah satu alasan kenapa harus menguasai PHP untuk menjadi web development yang hebat.[10]

\section{f) Bootstrape}

Bootstrape adalah sebuah framework CSS yang menyediakan kumpulan komponenkomponen antar muka dasar pada web yang telah dirancang sedemikian rupa untuk digunakan bersama-sama. Selain itu komponen antara muka, Bootstrape juga menyediakan sarana untuk membangun layout halaman dengan mudah dan rapi, serta modifikasi pada tampilan dasar HTML untuk membuat seluruh halaman web yang dikembangkan senada dengan komponen-komponen lainnya, Bootstrape di buat untuk memberikan sekumpulan perangkat yang dapat digunakan untuk membangun website sederhana dengan mudah.

Twitter Bootstrape dibangun dengan teknologi HTML dan CSS yang dapat membuat layout halaman website, tabel, tombol, form, navigasi, dan komponen lainnya dalam sebuah website hanya dengan memanggil fungsi CSS (class) dalam berkas HTML yang telah di definisikan. Selain itu juga terdapat komponenkomponen lainnya yang dibangun menggunakan JavaScript.[11]

\section{g) Sublime Text}

Sublime Text adalah salah satu program yang digunakan untuk melakukan editor seperti HTML, PHP, CSS. Program editor mudah digunakan dan dapat download secara free alias gratis.[12]

\section{h) MySql}

MYSQL adalah sebuah perangkat lunak sistem manajemen basis data SQL atau DBMS yang multithierd, multi-user, dengan sekitar 6 juta instalasi di seluruh dunia. MYSQL AB membuat MYSQL tersedia sebagai perangkat lunak gratis di lisensi GNU General publik License (GPL), tetapi mereka juga menjual di bawah lisensi komersial untuk kasus-kasus dimana penggunaanya tidak cocok dengan penggunaan GPL.[13]

\section{i) Jquery}

Jquery merupakan salah satu dari sekian banyak JavaScript library yaitu kumpulan fungsi Javascript yang siap pakai, sehingga 
mempermudah dan mempercepat dalam membuat kode Javascript. Dengan menggunakan jQuery, skrip JavaScript yang panjang dapat disingkat menjadi beberapa baris kode saja.[14]

\subsection{Tahapan Pengembangan Sistem}

Metode pengembangan sistem yang digunakan dalam penelitian ini adalah sebagai berikut :

\section{a) Analisis}

Pada tahap ini dilakukan analisis terhadap aplikasi atau sistem yang akan dibangun berikut ini adalah beberapa analisis yang perlu dilakukan dalam membangun website pada Kelurahan Melayu Tenggarong:

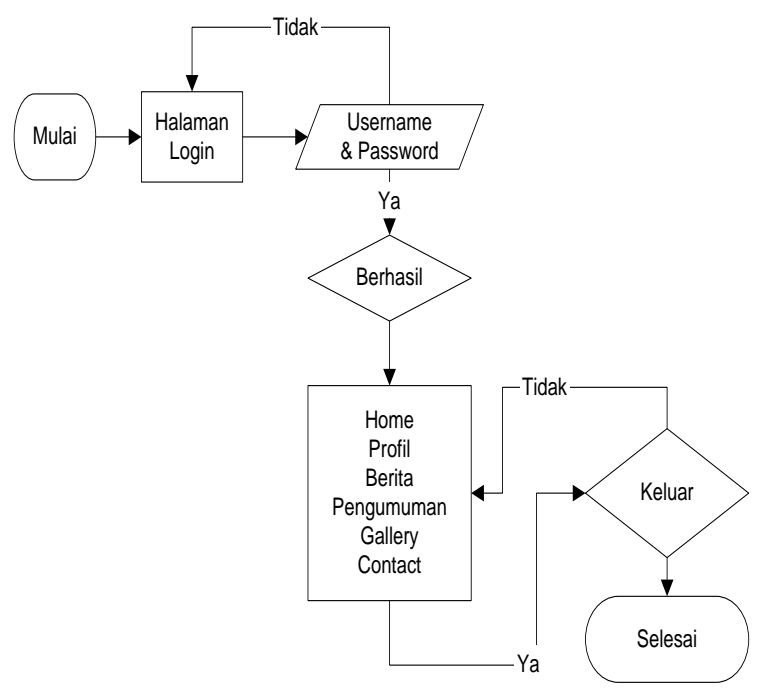

\section{Gambar 1. Flowchart Admin}

Pada Gambar 1. menggambarkan bagaimana admin login ke dalam system untuk melakukan proses manajemen website jika berhasil maka akan masuk kehalaman manajemen website namun jika gagal akan kembali kebagian form login.

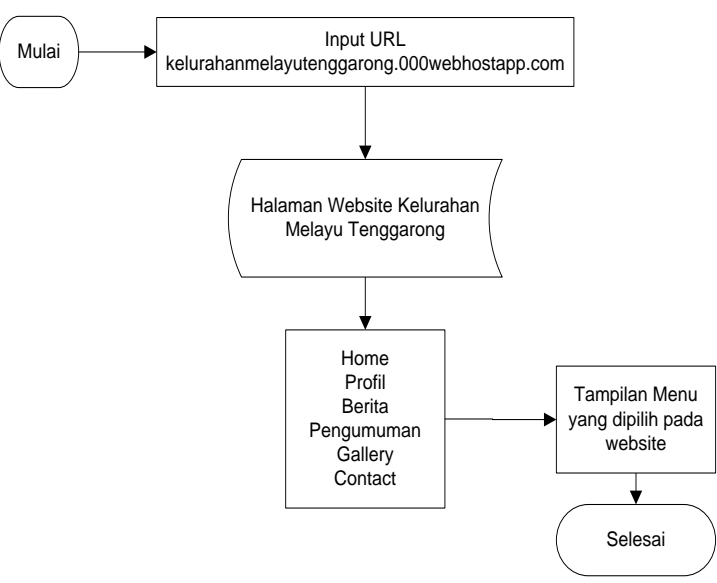

Gambar 2. Flowchart User

Pada Gambar 2. menggambarkan bagaimana pengguna website mengunjungi halaman Website Profile Kelurahan Melayu Tenggarong, dari menuliskan alamat website kemudian menunggu sampai halaman website tertampil, jika halaman sudah tampil maka pengunjung dapat mengklik link-link yang terdapat pada halaman Website Profile Kelurahan Melayu Tenggarong sesuai dengan informasi yang diinginkan

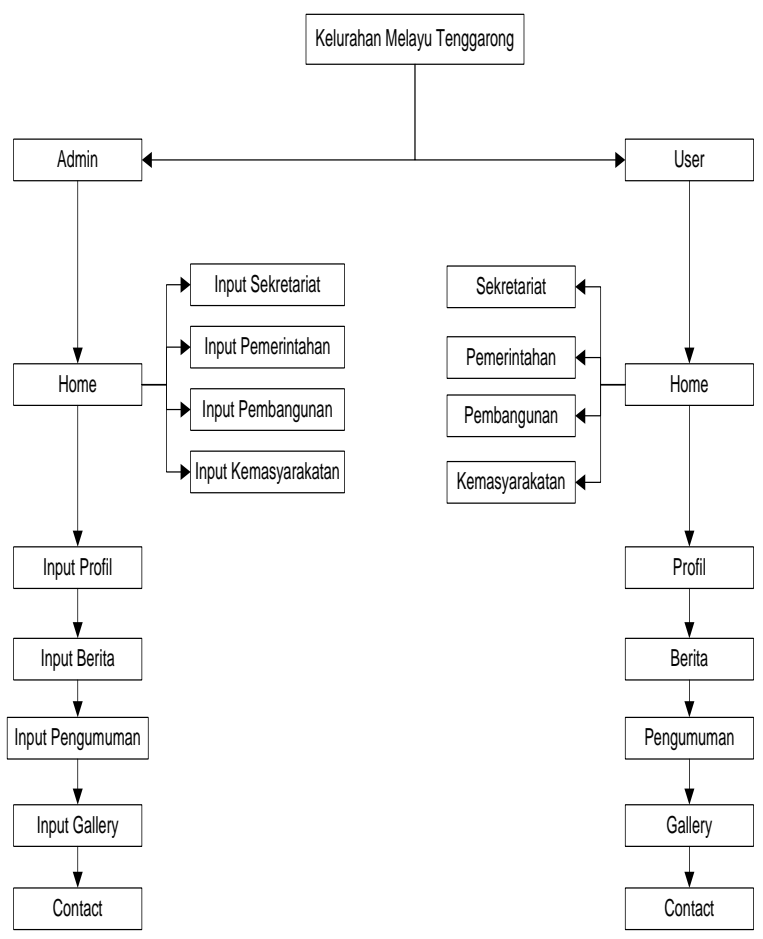

Gambar 3. Sitemap Kelurahan Melayu Tenggarong 
Pada Gambar 3. menunjukan hubungan antar navigasi link pada website Kelurahan Melayu Tenggarong dibagi atas halaman pengguna / user yang terdiri dari halaman Home, halaman profil, berita, pengumuman, gallery selanjutnya adalah halaman Contact. Pada bagian halaman admin terdiri atas halaman : home, input sekretariat, input pemerintahan, input pengumuman, input kemasyarakatan, input profil, input berita, input pengumuman, input gallery, contact.

\section{b) Desain Sistem}

Desain sistem merupakan salah satu bagian yang sangat penting dalam penyusunan laporan penulisan ilmiah, pada sebuah desain sistem akan dilihat fungsi dan peran masingmasing data yang terkumpul dalam membentuk sebuah sistem/ program, desain sistem yang digunakan dalam penelitian ini adalah [10]

1) Struktur Database

Struktur basis data dimaksudkan untuk mengidentifikasikan kebutuhan yang diperlukan oleh Website profile Kelurahan Melayu Tenggarong, Adapun struktur basis data yang diperlukan dalam membangun sistem atau aplikasi adalah:

\section{Tabel Admin}

Tabel 1 adalah tabel admin dimana digunakan untuk pemeliharaan data admin. Tabel admin ini memiliki primary key yaitu field "Id".

Tabel 1. Struktur tabel admin

\begin{tabular}{|c|c|c|c|}
\hline Nama & Tipe Data & Ukuran & Ket \\
\hline $\mathrm{Id}$ & Int & 11 & Id user \\
\hline Username & Varchar & 40 & $\begin{array}{l}\text { Usern } \\
\text { ame }\end{array}$ \\
\hline Password & Varchar & 40 & $\begin{array}{l}\text { Passw } \\
\text { ord }\end{array}$ \\
\hline
\end{tabular}

\section{Tabel Berita}

Tabel 2 adalah tabel berita dimana digunakan untuk menyimpan data berita yang ada pada halaman pengunjung. Tabel berita ini memiliki primary key yaitu field "Id_berita".

\section{Tabel 2. Struktur tabel Berita}

\begin{tabular}{|c|c|c|c|c|}
\hline No & Nama & $\begin{array}{l}\text { Tipe } \\
\text { Data }\end{array}$ & $\begin{array}{c}\text { Ukura } \\
\text { n }\end{array}$ & $\begin{array}{c}\text { Keteranga } \\
\text { n }\end{array}$ \\
\hline 1 & Id_berita & Int & 11 & Id Berita \\
\hline 2 & $\begin{array}{l}\text { Gambar_ } \\
\text { berita }\end{array}$ & $\begin{array}{l}\text { Varcha } \\
\mathrm{r}\end{array}$ & 200 & $\begin{array}{l}\text { GambarBeri } \\
\text { ta }\end{array}$ \\
\hline 3 & $\begin{array}{l}\text { Judul_be } \\
\text { rita }\end{array}$ & Text & - & Judul Berita \\
\hline 4 & Isi_berita & Text & - & Isi Berita \\
\hline 5 & Author & $\begin{array}{l}\text { Varcha } \\
\mathrm{r}\end{array}$ & 30 & Author \\
\hline
\end{tabular}

\section{Tabel Gallery}

Tabel 3 adalah tabel gallery dimana digunakan untuk menyimpan gambar yang terdapat pada halaman pengunjung.

Tabel 3. Struktur tabel Gallery

\begin{tabular}{|c|c|c|c|}
\hline Nama & $\begin{array}{l}\text { Tipe } \\
\text { Data }\end{array}$ & Ukuran & Keterangan \\
\hline Id_gambar & Int & 11 & Id Gambar \\
\hline nama_gambar & Varchar & 200 & $\begin{array}{l}\text { Nama } \\
\text { Gambar }\end{array}$ \\
\hline judul_gambar & Varchar & 300 & $\begin{array}{l}\text { Judul } \\
\text { Gambar }\end{array}$ \\
\hline
\end{tabular}

\section{Tabel Kemasyarakatan}

Tabel 4 adalah tabel kemasyarakatan dimana digunakan untuk menyimpan informasi kemasyarakatan.

Tabel 4. Struktur tabel Kemasyarakatan

\begin{tabular}{|c|c|c|c|}
\hline Nama & $\begin{array}{l}\text { Tipe } \\
\text { Data }\end{array}$ & Ukuran & Keterangan \\
\hline id_kesra & Int & 11 & $\begin{array}{l}\text { Id } \\
\text { kemasyarakataan }\end{array}$ \\
\hline foto_kesra & Varchar & 225 & $\begin{array}{l}\text { Foto } \\
\text { kemasyarakataan }\end{array}$ \\
\hline judul_kesra & Text & - & $\begin{array}{l}\text { Judul } \\
\text { kemasyarakataan }\end{array}$ \\
\hline isi_kesra & Text & - & $\begin{array}{l}\text { Isi } \\
\text { kemasyarakataan }\end{array}$ \\
\hline
\end{tabular}




\section{Tabel Pembangunan}

Tabel 5 adalah tabel pembangunan dimana digunakan untuk menyimpan data pembangunan pada halaman admin.

Tabel 5. Struktur tabel Pembangunan

\begin{tabular}{|c|c|c|c|}
\hline Nama & $\begin{array}{l}\text { Tipe } \\
\text { Data }\end{array}$ & Ukuran & Keterangan \\
\hline $\begin{array}{l}\text { id_- } \\
\text { pembangunan } \\
\text { foto_ } \\
\text { pembangunan } \\
\text { judul_ } \\
\text { pembangunan } \\
\text { isi_ } \\
\text { pembangunan }\end{array}$ & $\begin{array}{l}\text { Int } \\
\text { Varchar } \\
\text { Text } \\
\text { Text }\end{array}$ & $\begin{array}{l}11 \\
225 \\
-\end{array}$ & $\begin{array}{l}\text { Id table } \\
\text { pembangunan } \\
\text { Foto } \\
\text { pembangunan } \\
\text { Judul } \\
\text { pembangunan } \\
\text { Isi } \\
\text { pembangunan }\end{array}$ \\
\hline
\end{tabular}

\section{Tabel Pemerintahan}

Tabel 6 adalah tabel pemerintahan dimana digunakan untuk menyimpan data pemerintahan pada halaman admin.

Tabel 6. Struktur tabel Pemerintahan

\begin{tabular}{|c|c|c|c|}
\hline Nama & $\begin{array}{l}\text { Tipe } \\
\text { Data }\end{array}$ & Ukuran & Keterangan \\
\hline $\begin{array}{l}\text { Id_- } \\
\text { pemerintahan } \\
\text { foto_ } \\
\text { pemerintahan } \\
\text { judul_ } \\
\text { pemerintahan } \\
\text { isi_ } \\
\text { pemerintahan }\end{array}$ & $\begin{array}{l}\text { Int } \\
\text { Varch } \\
\text { ar } \\
\text { Text } \\
\text { Text }\end{array}$ & $\begin{array}{l}11 \\
225 \\
- \\
-\end{array}$ & $\begin{array}{l}\text { Id } \\
\text { pemerintahan } \\
\text { Foto } \\
\text { pemerintahan } \\
\text { Judul } \\
\text { pemerintahan } \\
\text { Isi } \\
\text { pemerinthan }\end{array}$ \\
\hline
\end{tabular}

\section{Tabel Pengumuman}

Tabel 7 adalah tabel pengumuman dimana digunakan untuk mengumumkan di halaman pengunjung.

\section{Tabel 7. Struktur tabel Pengumuman}

\begin{tabular}{|c|c|c|c|}
\hline Nama & $\begin{array}{l}\text { Tipe } \\
\text { Data }\end{array}$ & Ukuran & Keterangan \\
\hline id_ & Int & 11 & $\mathrm{Id}_{-}$ \\
\hline pengumuman & & & pengumuman \\
\hline gambar_- & Varchar & 225 & Gambar \\
\hline judul_ & Varchar & 50 & Judul \\
\hline pengumuman & & & pengumuman \\
\hline $\begin{array}{l}\text { isi_ } \\
\text { pengumuman }\end{array}$ & Text & - & $\begin{array}{l}\text { Isi } \\
\text { pengumuman }\end{array}$ \\
\hline Author & Varchar & 50 & Penulis \\
\hline
\end{tabular}

Tabel profil

Tabel 8 adalah tabel profil dimana digunakan untuk menyimpan data profil.

Tabel 8. Struktur tabel Profil

\begin{tabular}{l|l|l|l}
\hline \multicolumn{1}{c|}{ Nama } & $\begin{array}{c}\text { Data } \\
\text { Type }\end{array}$ & Ukuran & Keterangan \\
\hline id_profil & Int & 11 & Id_profil \\
foto_profil & Varchar & 300 & Foto profil \\
nama_profil & Varchar & 300 & Nama profil \\
isi_profil & Text & - & Isi profil \\
Author & Varchar & 30 & Penulis \\
\hline
\end{tabular}

\section{Tabel Sekretariat}

Tabel 9 adalah tabel sekretariat dimana digunakan untuk menyimpan data sekretariat.

Tabel 9. Struktur Tabel Sekretariat

\begin{tabular}{l|l|l|l}
\hline \multicolumn{1}{c|}{ Nama } & $\begin{array}{c}\text { Tipe } \\
\text { Data }\end{array}$ & Ukuran & Keterangan \\
\hline $\begin{array}{l}\text { id_- } \\
\text { sekretariat }\end{array}$ & Int & 11 & $\begin{array}{l}\text { Id_- } \\
\text { sekretariat }\end{array}$ \\
\hline $\begin{array}{l}\text { foto_ } \\
\text { sekretariat }\end{array}$ & $\begin{array}{l}\text { Varcha } \\
\text { r }\end{array}$ & 225 & $\begin{array}{l}\text { Foto } \\
\text { sekretariat }\end{array}$ \\
\hline $\begin{array}{l}\text { judul_ } \\
\text { sekretariat }\end{array}$ & Text & - & $\begin{array}{l}\text { Judul } \\
\text { sekretariat }\end{array}$ \\
\hline $\begin{array}{l}\text { isi_- } \\
\text { sekretariat }\end{array}$ & Text & - & $\begin{array}{l}\text { Isi } \\
\text { sekretariat }\end{array}$ \\
\hline
\end{tabular}

\section{HASIL DAN PEMBAHASAN}

Desain yang sudah dibuat akan diwujudkan dalam bentuk program nyata yang dapat digunakan baik itu berupa form halaman website dan query dari data [15]. Gambar 4 menampilkan gambar halaman utama website ini yang terdiri dari tampilan navigasi menu dan tampilan artikel pada berandanya tentang sekretariat, pemerintahan, pembangunan, kemasyarakatan. Pada halaman ini user atau pengunjung dapat membaca artikel. Halaman Utama dimana setiap pengguna sistem ini akan secara otomatis memasuki halaman ini disaat pertama kali menggunakan sistem ini. 
Halamana Utama dibuat sesederhana mungkin desain tampilannya agar masyarakat sekitar atau pengunjung website tersebut dengan mudah dapat menggunakannya.

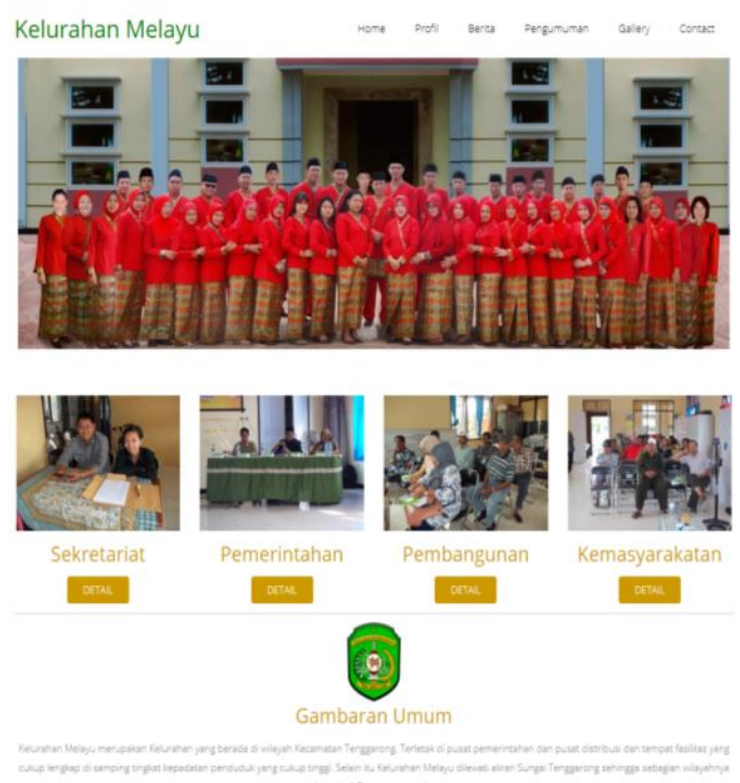

\section{Gambar 4. Halaman Utama}

Gambar 5 Menampilkan gambar halaman sekretariat pada website yang terdiri dari tampilan navigasi menu dan tampilan artikel pada berandanya tentang sekretariat. Halaman ini menginformasikan tugas pelayanan sekretariat agar mempermudah masyarakat untuk memenuhi persyaratan yang diperlukan yang berhubungan dengan tugas pelayanan dari kasi sekretariat.

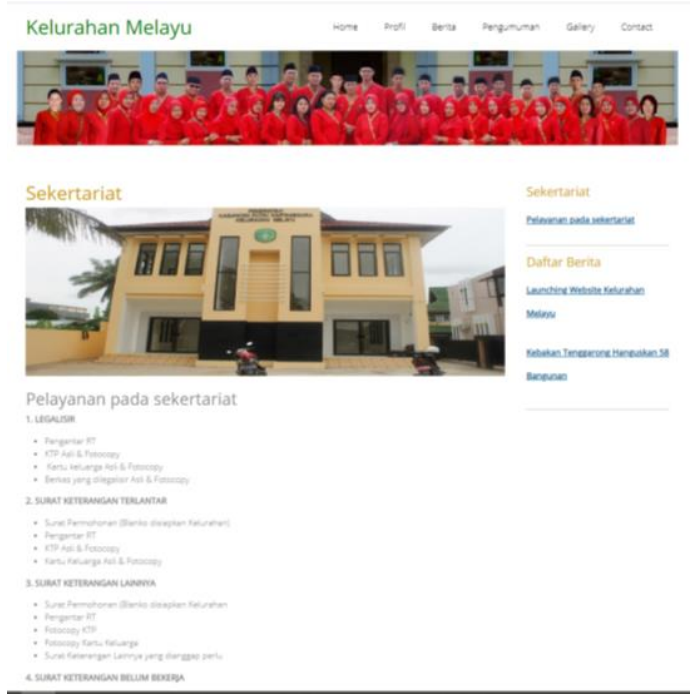

Gambar 5. Halaman Sekretariatan
Gambar 6 Menampilkan gambar halaman pemerintahan pada website yang terdiri dari tampilan navigasi menu dan tampilan artikel pada berandanya tentang pemerintahan. Halaman ini menginformasikan tugas pelayanan pemerintahan agar mempermudah masyarakat untuk memenuhi persyaratan yang diperlukan yang berhubungan dengan tugas pelayanan dari kasi pemerintahan.

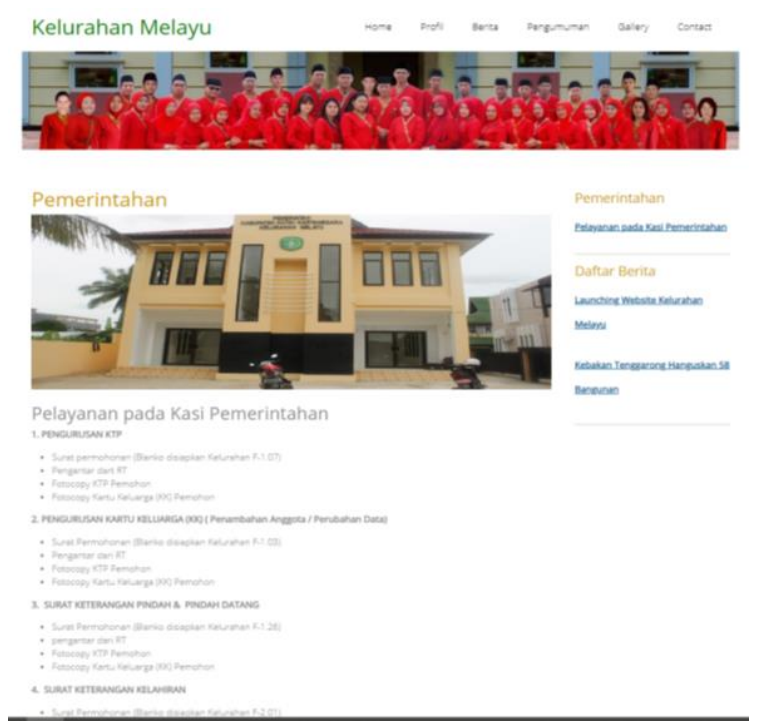

Gambar 6. Halaman Pemerintahan

Gambar 7 Menampilkan gambar halaman pembangunan pada website ini yang terdiri dari tampilan navigasi menu dan tampilan artikel pada berandanya tentang pembangunan. Halaman ini menginformasikan tugas pelayanan pembangunan agar serta mempermudah masyarakat untuk memenuhi persyaratan yang diperlukan yang berhubungan dengan tugas pelayanan dari kasi pembangunan seperti surat keterangan usaha, surat keterangan domisili usaha, keterangan IMB, keterangan belum memiliki IMB, surat pengantar PBB, surat keterangan pembetulan mutasi atas $\mathrm{PBB} / \mathrm{balik}$ nama, penyampaian SPPT PBB P2, surat keterangan pengurusan NPWP, surat keterangan koperasi, surat keterangan kelompok usaha. 


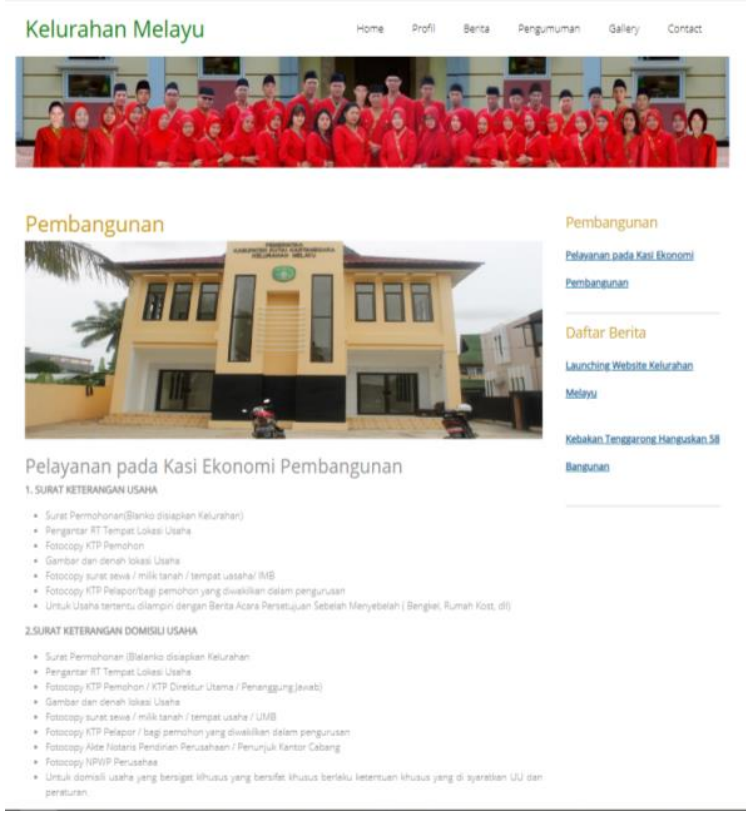

\section{Gambar 7. Halaman Pembangunan}

Gambar 8 Menampilkan gambar halaman sosial kemasyarakatan pada website yang terdiri dari tampilan navigasi menu dan tampilan artikel pada berandanya tentang sosial kemasyarakatan. Halaman ini menginformasikan tugas pelayanan sosial kemasyarakatan agar mempermudah masyarakat untuk memenuhi persyaratan yang diperlukan.

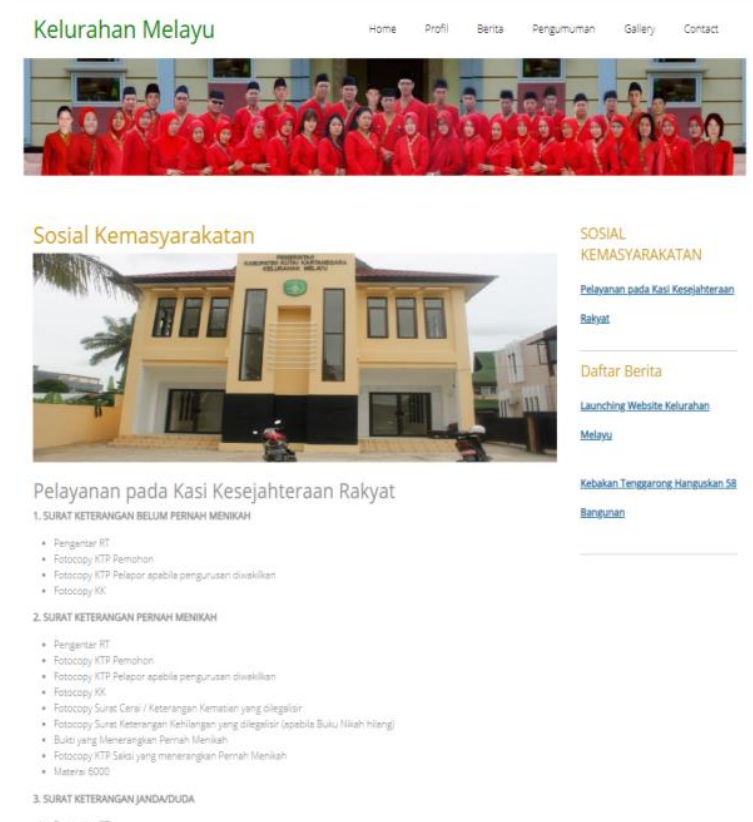

Gambar 8. Halaman Sosial Kemasyarakatan
Gambar 9 menampilkan gambar halaman profil, pada halaman ini para pengunjung dapat melihat profile dari Kelurahan Melayu Tenggarong. Dalam halaman ini akan menampilkan sejarah singkat tentang Kelurahan Melayu Tenggarong, Visi Misi Kelurahan Melayu Tenggarong, Struktur Organisasi, Lokasi Kantor Kelurahan Melayu Tenggarong beserta daftar wilayah-wilayah RT di Kelurahan Melayu Tenggarong.

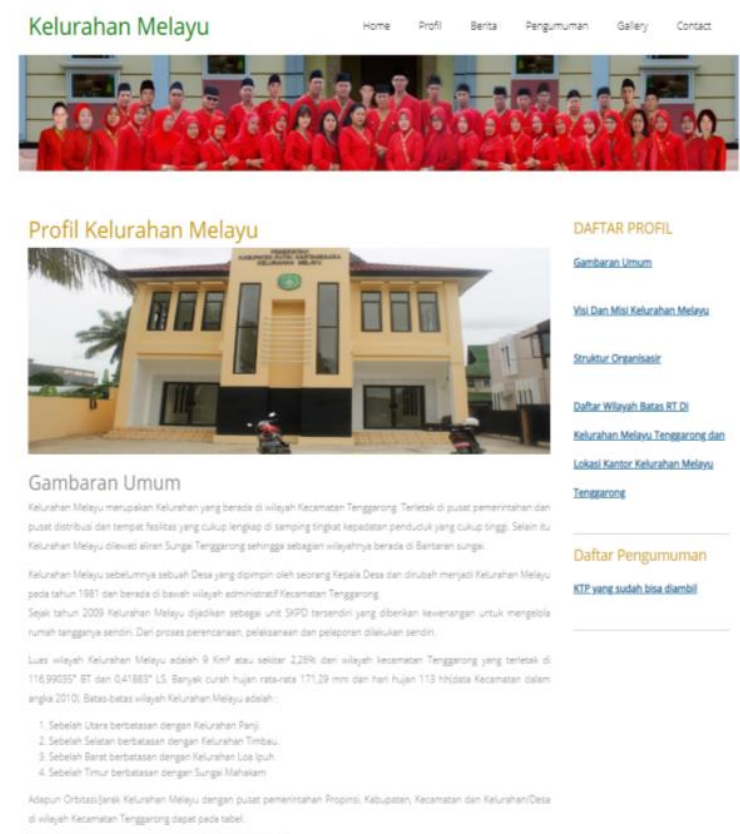

Gambar 9. Halaman Profil

Gambar 10 adalah halaman berita. Pada Halaman ini pengunjung dapat melihat info-info berita penting untuk masyarakat sekitar yang lebih update sehingga mempermudah masyarakat agar lebih efektif dan efisien untuk mengetahui berita
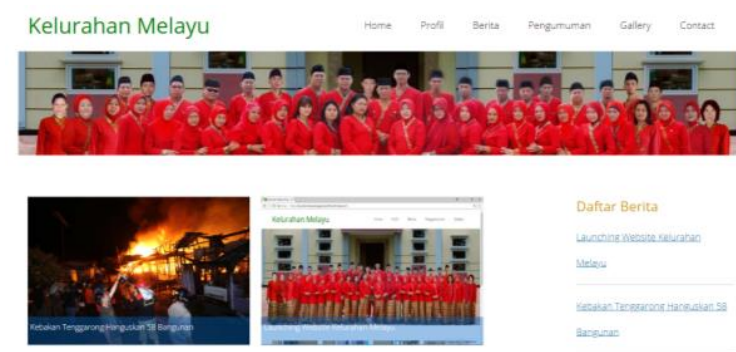

\section{Gambar 10. Halaman Berita}




\section{KESIMPULAN}

Dengan adanya website yang telah dibangun akan mempermudah Kelurahan Melayu dalam menyebarkan informasi maupun berita mengenai Kelurahan Melayu Tenggarong dan dapat terpublikasi dengan baik. Dengan demikian informasi dapat dilihat oleh semua orang khususnya masyarakat dan Kelurahan Melayu yang membutuhkan informasi tentang Kelurahan Melayu Tenggarong. Pada Website ini pengunjung dapat memberi komentar atau pendapatnya mengenai berita kegiatan, pengumuman, atau apapun itu yang di publikasikan.

Diharapkan juga adanya pengembangan terhadap website ini menjadi sebuah website yang lebih lengkap lagi, misalnya dapat berdiskusi melalui video pada website Kelurahan Melayu Tenggarong dan Diharapkan juga website ini dapat melakukan sistem pendaftaran online untuk Pemilihan Kepala Lurah.

\section{UCAPAN TERIMA KASIH}

Judul Dibiayai oleh Direktorat Riset dan Pengabdian Masyarakat Direktorat Jenderal Penguatan Riset dan Pengembangan Kementerian Riset, Teknologi, dan Pendidikan Tinggi sesuai Dengan Kontrak Penelitian Tahun Anggaran 2020

\section{DAFTAR PUSTAKA}

[1] Hutahaean, J. 2014. Konsep Sistem Informasi. Yogyakarta: CV. Budi Utama. Ichwan, M. 2011. Pemograman Basis Data Delphi 7 \& MySQL. Bandung: Informatika Bandung.
[2] Antonio, H., \& Safriadi, N. 2012. Rancang Bangun Sistem Informasi Administrasi Informatika.

[3] Abdulloh. 2015. Web Programming Is Easy, Jakarta : PT. Elex Medi Komputindo.

[4] Febrian, Jack, 2010, Menggunakan Internet, Bandung : Informatika.

[5] Comminity,. 2011 Langkah Muda Menjadi Web Master, Jakarta : Mediakita.

[6] Indrajani, 2014. Pengantar Sistem Basis Data Case Study All In One, Jakarta : ElexMedia Komputindo.

[7] Rohy. 2015. PHP pemograman web!, Jakarta: Jasakom.

[8] Ardhana, YM Kusuma. 2012. PHP menyelesaikan Web 30 Juta!, Jakarta:Jasakom.

[9] Jauhari, Khairul, 2014, Step by step : Web Design Theory and Practice.

[10] Jogiyanto, 2010. Analisis dan Desain Sistem Informasi, Yogyakarta : Penerbit Andi.

[11] Madcoms. 2009. Membongkar Misteri Internet, Madiun : Penerbit Andi mysql rev 2, Bandung: Modula.

[12] Jakung, L. K. 2013. Aplikasi Penjualan Pada Butik Sally Lovely Berbasis Web Menggunakan Program PHP.

[13] Suhadi,Mustazzihim,2016,pengertian Mysql, Jakarta : Informatika Yogyakarta : Andi Offset.

[14] Firmansyah, M. A., \& Fatihudin, D. 2017. Globalisasi Pemasaran (Marketing Globalization). Deepublish.

[15] Andini, T. D., \& Zulkarnain, A. Suggestions Friends Engine Berbasis Hybrid Recommender System Untuk Mendapatkan Rekomendasi Teman Terbaik Pada Web Jejaring Sosial. 2013. 